\title{
Compassion Fatigue: The Experiences of Teachers Working with Students with Exceptionalities
}

\author{
Newsha Ziaian-Ghafari and Derek H. Berg \\ Queen's University
}

\begin{abstract}
The purpose of this study was to explore the social-emotional experience of teachers working with students with exceptionalities in the general education classroom. Individual interviews were conducted with five participants with in-service teaching experience. While these teachers highlighted experiencing burnout, the breadth and depth of their experiences with respect to psychological distress were more profoundly situated within compassion fatigue. Considering the root of burnout as being related to workload conditions and that of compassion fatigue being rooted in social-emotional relationships with students, it is possible that compassion fatigue and burnout emerge along parallel trajectories of psychological distress in teachers.
\end{abstract}

Recent statistics indicate a significant number of students in Canada are identified as being in need of specialized educational support (Learning Disabilities Association of Ontario [LDAO], 2018; Statistics Canada, 2008). In 2015, approximately 17\% of students with unidentified exceptionalities were receiving specialized educational supports and services in Ontario (LDAO, 2018). The number of students with identified and unidentified exceptionalities is growing in Canada, with some regions reporting an approximate ratio of 37 students with exceptionalities for every teacher with special education qualifications (People for Education, 2015).

While there is some consistency in the definition of exceptionalities across provincial and territorial educational authorities, there is no consensus about either the conceptual or operational definition for individual exceptionalities. Similarly, within local school boards across Canada there often emerge different philosophical approaches to placements (e.g., withdrawal to resources rooms) or in-class supports that 
utilize instructional approaches such as Universal Design for Learning and differentiated instruction to support students with exceptionalities. The Ontario Ministry of Education has defined a student with exceptionalities as "a pupil whose behavioural, communicational, intellectual, physical or multiple exceptionalities are such that he or she is considered to need placement in a special education program by a committee" (Ontario Ministry of Education, 2017, p. 19). Within each of these categories of exceptionality exists a range of disabilities, challenges, strengths, and specific educational needs that a student may bring into the classroom. In this sense, teachers are similar to those in other helping professions, such as nurses and social workers, whose clients can present a range of acute and chronic conditions and experiences that necessitate a diversity of supports (Graff, Millar, Feilteau, Coakley, \& Erickson, 2003).

Across the full inclusion model of public education in Canada, general classroom teachers frequently report that they lack adequate training and resources necessary to successfully meet the needs of students with exceptionalities (Connelly \& Graham, 2009). Moreover, teachers working with exceptional students are subject to a range of mental health challenges that are comparable to other human-service workers, such as nurses and work counsellors (Putnik, Jong, \& Verdonk, 2011; Van Droogenbroeck \& Spruyt, 2015). Across these professions, mental health challenges can follow a trajectory toward psychological distress that can manifest as burnout or compassion fatigue.

Chronic and extreme stress from occupational demands can negatively affect mental health for individuals (Desrumaux et al., 2015). Burnout and compassion fatigue are two constructs of psychological distress that can inform our understanding of teachers' social and emotional experiences. General classroom teachers are expected to balance the tremendous professional responsibilities of being an educator for a wide range of individual and group instructional needs in order to establish a level of emotional and social support that creates a positive learning environment. Beyond these considerations (i.e., the successful inclusion of students with exceptionalities, who typically experience more significant academic, cognitive, social, and emotional challenges than typically developing students) the role of a classroom teacher includes the complexities of navigating relationships with parents or guardians and other educational professionals in creating a fully inclusive setting (Hillel Lavian, 2015).

Burnout is characterized by feelings of emotional exhaustion (e.g., feeling drained), depersonalization (e.g., callousness toward others), and reduced feelings of personal accomplishment (e.g., feeling ineffective) resulting from chronic work stress (Maslach, 2003; Maslach \& Jackson, 1981). Typically reported in nurses and social workers, compassion fatigue is characterized by feelings of depression, anxiety, and reduced empathy resulting from repeated exposure to the distress of vulnerable populations (Figley, 2002; Najjar, Davis, Beck-Coon, \& Carney Doebbeling, 2009). With a significant reduction in their compassion and empathy, individuals experiencing compassion fatigue no longer feel psychologically capable of providing care to their clients. Both burnout and compassion fatigue fall under the umbrella of poor mental health; nonetheless, there is a critical distinction between these constructs of psychological distress. While burnout is the result of workload conditions, compassion fatigue develops from the impulse to help others and is rooted in the social-emotional 
relationship between a professional and their client. Experiences consistent with burnout and compassion fatigue have been previously reported by teachers (e.g., Connelly \& Graham, 2009; Hoffman, Palladino, \& Barnett, 2007). Bride, Radey, \& Figley (2007) defined compassion fatigue as the emotional, behavioural, and cognitive changes experienced by mental health professionals through indirect exposure to the trauma of their clients. In existing literature, compassion fatigue is sometimes referred to as vicarious traumatization or secondary traumatic stress (Bride et al., 2007). In contrast, some professionals experience positive balance through their work in helping traumatized or suffering individuals; this is referred to as compassion satisfaction (Bride et al., 2007; Perry, Brenner, Collie, \& Hofer, 2015). Individuals in psychological distress tend to feel depleted and stagnant, while those who experience satisfaction from supporting individuals can be considered to be thriving and are typically growing, developing, and feeling energized in their work.

\section{Special Education}

Teachers working with students with exceptionalities often report challenging social-emotional experiences in their early career (Schlichte, Yssel, \& Merbler, 2005). Within the classroom, teachers must balance interpersonal demands as they strive to adapt instruction, curriculum, and assessment to meet the diverse needs of their students, and in particular those students with exceptionalities. Challenges associated with meeting these demands can place teachers at risk for burnout and compassion fatigue. Indeed, teachers who work directly with exceptional students within selfcontained classrooms or through withdrawal programs, report significant socialemotional challenges. In these circumstances, many consider leaving the profession despite also highlighting the potentially rewarding nature of their relationship with students (Schlichte et al., 2005).

Research has identified working with students with exceptionalities as a significant area of concern for early career teachers. This sub-population of educators highlights the importance of sufficient training and preparation for effectively supporting students with exceptionalities and the social-emotional challenges that may be experienced by teachers working in general or special education classroom contexts. Conderman, Johnston-Rodriguez, Hartman, \& Walker (2012) asked 64 recent graduates of a teacher education program to complete a survey regarding their views on their preparedness to work with students with exceptionalities prior to gaining professional experience. Results suggested that these new teachers felt the practicum experience during their teacher training was most beneficial in preparing students to become special educators, as it provided opportunities to engage with students using practical approaches in realworld school settings. Conderman et al. (2012) also reported that the novice teachers recommended additional training in classroom management and working with students with high-needs exceptionalities such as autism spectrum disorder (ASD). The importance of specialized training in the field of exceptional learners during teacher education has been underscored in the literature, with such programming increasing the self-efficacy of teachers to meet the needs of students with exceptionalities (Wash \& Freeman, 2014). An opposite trajectory is also possible; teachers who lack effective training for the vagaries of working with students with exceptionalities are at risk of 
reduced self-efficacy in classroom management and the significant challenges that emerge from an absence of adequate preparation to support the individual and group needs of students with exceptionalities.

Brackenreed and Barnett (2006) examined pre-service teachers' self-perceptions of stress and their beliefs related to inclusion and classroom management. Questionnaires were collected from 428 teacher candidates enrolled in a Bachelor of Education program. All participants took mandatory classes in classroom management and special education. Overall, participants reported a lack of confidence in dealing with students with limited speech, mental health challenges such as depression, avoidance behaviours, and students engaging sexually explicit behaviour (Brackenreed \& Barnett, 2006). These teacher candidates also expressed being only somewhat confident in meeting their own needs in the classroom.

Pre-service teachers across the educational fields generally express anxiety toward working with students with exceptional needs (Everhart, 2009). Everhart (2009) found that teacher candidates communicated that they were anxious about working with students with disabilities within classroom settings. The recommended solution for easing the anxiety of pre-service teachers in working with students with exceptionalities was to allow opportunities for them to engage in practical experience with students with special needs during their teacher training program (Everhart, 2009).

Everhart's findings reflected those of an earlier study by Shippen, Crites, Houchins, Ramsey, \& Simon (2005), which investigated the perceptions of preservice teachers regarding the inclusion of students with disabilities. The authors advocated that considering the shift to a full inclusion model, it is the duty of teacher education programs to prepare both general classroom and special education teachers with the knowledge and skills to work effectively with students with exceptionalities (Shippen et al., 2005).

Schlichte et al. (2005) aimed to identify risk factors associated with burnout and examine the experiences of special education teachers during their first year in the classroom. Four of the five participants did not consider their first year of teaching a success, and reported feeling isolated and alienated within the school, lacking the support of a mentor or administrator, and feeling negative emotions about continuing in the profession (Schlichte et al., 2005). Although a positive relationship with students was emotionally rewarding to the first-year special educators, all four participants with negative experiences stated that they had seriously considered leaving the profession, and two of these teachers resigned by the end of the school year.

Connelly and Graham (2009) reported findings on a broader scale with early career teachers who had recently completed their teacher education program. Of those special education teachers who had completed 10 or more weeks of practicum in a special education setting, $80 \%$ were teaching special education one year later, $7 \%$ had moved to a different field within education, and $14 \%$ had left the profession. In contrast, of those special education teachers who had completed less than 10 weeks of practicum within a special education setting, $63 \%$ were teaching special education one year later, while $16 \%$ had moved to a different field within education, and $20 \%$ had left the profession. Connelly and Graham (2009) interpreted these findings as evidence for the benefit of 
additional practicum experience of special educators during teacher preparation programs, with the practicum acting as a protective factor against psychological distress related to burnout and against the disillusionment that beginning teachers experience working with students with exceptionalities. These findings might also highlight the potential benefit in increasing self-efficacy, self-care, and coping strategies of early career teachers working with students with exceptionalities in reducing teachers' risk of experiencing psychological distress and ultimately reduce overall attrition (Brackenreed \& Barnett, 2006).

\section{Burnout}

The construct of burnout, first introduced by Maslach (Maslach, 2003; Maslach \& Jackson, 1981), is often used in literature to describe the negative emotional experience of professionals working in a human-services role. In current research, the chronic negative emotion of teachers is typically operationalized as burnout (Van den Berghe et al., 2014). Research on the topic of burnout in educational settings is widespread, with various studies looking at the relationships between teacher burnout and factors such as school resources, student misbehaviour, classroom management, self-efficacy, and motivation (Brouwers \& Tomic, 2000; Emery \& Vandenberg, 2010). Though in extant literature burnout is generally operationalized as a stable construct, research by Hultell, Melin, and Gustavsson (2013) considered the difference in trajectory for individual experiences of burnout. In a longitudinal study of burnout in 816 beginning teachers across the first three years of their career, Hultell et al. found that burnout remained relatively consistent; however, burnout levels appeared to follow one of seven paths over the three years: (a) a significant increase from an initial low level $(13 \%)$, (b) a minor decrease from a high initial level $(11 \%)$, (c) a spike to a high level from an initial low level followed by an approximate return to the initial low level $(10 \%)$, (d) a decrease from an initial high level to a low level followed by an approximate return to the initial high level $(9 \%)$, (e) a stable low level across all three years $(25 \%)$, (f) a stable moderate level across all three years $(27 \%)$, and (g) a stable high level across all three years $(5 \%)$. These findings suggest that the initial experience of burnout in beginning teachers is not necessarily predictive of future career burnout (Hultell et al., 2013). Moreover, these patterns in the levels of experienced burnout are promising in terms of targeting particular levels and response times for prevention and intervention initiatives.

Skaalvik and Skaalvik (2010) examined the relationships among teachers' selfefficacy, job satisfaction, and burnout. Results from 2,249 teachers indicated that burnout was related to both self-efficacy and job satisfaction. More specifically, high levels of burnout were associated with low levels of self-efficacy and job satisfaction, with the emotional exhaustion element of burnout holding the strongest relationship to self-efficacy and job satisfaction. With respect to the current study, the importance of emotional exhaustion in understanding teachers' self-efficacy and job satisfaction highlighted in Skaalvik and Skaalvik (2010) suggests an important avenue for understanding teachers' occupational engagement and perhaps their social-emotional experiences. 


\section{Compassion Fatigue}

Though burnout has been the predominant lens through which teachers' socialemotional experiences in the classroom have been examined (e.g., Hultell et al., 2013; Wang, Hall, \& Rahimi, 2015), compassion fatigue offers an additional lens through which to understand the experience of teachers working with students with exceptionalities in an inclusive classroom context. In particular, the present study addressed the potential of compassion fatigue for understanding psychological distress experienced by teachers. Generally defined as an awareness of the suffering of others and an impulse to relieve that suffering (Radey \& Figley, 2007), compassion fatigue brings a novel perspective in examining the social and emotional experiences of the teachers who have committed their careers to educating students with special needs.

Bride et al. (2007) defined compassion fatigue as the emotional, behavioural, and cognitive changes experienced by mental health professionals through indirect exposure to the trauma of their clients. In existing literature, because of professionals' distal psychosocial connection to their clients, compassion fatigue is sometimes referred to as vicarious traumatization and secondary traumatic stress (Bride et al., 2007). In contrast to psychological distress, some professionals experience positive effects through their work in helping traumatized or suffering individuals; this is referred to as compassion satisfaction (Bride et al., 2007; Perry et al., 2015). The experience of compassion fatigue has been found to affect negatively both the well-being of professionals and their ability to help their clients (Bride et al., 2007). With respect to educators, applying compassion fatigue when examining the psychological distress experienced by teachers of students with exceptionalities might provide additional insight into the nuanced experiences of educational professionals beyond what is known through the construct of burnout (Hoffman et al., 2007).

Compassion fatigue has most often been a focus in studies of frontline humanservice professionals (e.g., nurses, social workers). Najjar et al. (2009) examined compassion fatigue as experienced by cancer-care providers. Although these researchers focused upon a particular population of health care workers, the implications of the study's findings might be helpful in understanding the experiences of other humanservice providers as well as professionals in other work environments that are characterized by interpersonal relationships between caregivers (e.g., teachers) and their clients (e.g., students). The authors reported that when psychological distress was viewed as burnout, experiences that informed this characterization closely aligned with factors that underlie compassion fatigue, such as emphatic sensitivity and emotional engagement.

Radey and Figley (2007) discussed compassion fatigue in social workers. Similar to social workers who are emotionally connected to their clients, teachers also take on a position as significantly caring others for their students. Radey and Figley (2007) conceived compassion fatigue as resulting from direct exposure to the suffering (physical, social, and emotional) of their clients who do not receive adequate support in the workplace or at home. Consequently, professionals with compassion fatigue experience a disconnection with others, hopelessness, and emotional and physical exhaustion (Radey \& Figley, 2007). As mitigating factors, when professionals in human-service roles experience job satisfaction, feel a sense of control over stressors in the workplace, 
increase self-care, and resolve their previous traumas, compassion can significantly benefit individuals in providing care to clients (Radey \& Figley, 2007).

\section{Compassion Fatigue and Burnout Within the Education Context}

Although there has been an increase in attention directed toward examining compassion fatigue in educators (Hoffman et al., 2007; Tepper, 2007), there remains a dearth of study within the field; rarer are those studies that address compassion fatigue within particular educational contexts such as teachers of students with exceptionalities. Teaching as a profession is focused on providing care to students, thus placing educators in a human-services role. Hoffman, Palladino, and Barnett (2007) applied compassion fatigue as a framework in addition to burnout to examine the factors that influence the early exodus of teachers from classroom teaching. Hoffman et al. (2007) specified that depersonalization in burnout includes social distancing from personal and professional relationships, and may be accompanied by feeling unsympathetic or pessimistic toward the clients under care (Hoffman et al., 2007). This definition of depersonalization highlights the overlap that may be present in defining psychological distress of teachers. The authors stated that while burnout can be conceptualized as repeated exposure to significant stress resulting in a gradual increase of the burnout, compassion fatigue is conceptualized as secondary traumatization through the act of compassion (Hoffman et al., 2007). Compassion fatigue emerges suddenly and with intensity, and is characterized by feelings of helplessness, isolation, and disorientation, making it distinct from burnout (Hoffman et al., 2007). The authors contended that the three themes (i.e., loss of control, responsibility, and empathy) reported by participants were consistent with the conceptual definition of compassion fatigue (Hoffman et al., 2007). The teachers in this study had remained in the profession and described psychological distress that was multi-faceted and could be captured by experiences reflective of both compassion fatigue and burnout.

Using both burnout and compassion fatigue, Tepper (2007) sought to describe the relationship between the experiences of nine in-service teachers working in elementary special education classrooms. Tepper (2007) suggested that an overlap of symptoms could be found between burnout and compassion fatigue, and that compassion fatigue was comprised of both of burnout and secondary trauma. An important distinction suggested by the author was that burnout and compassion fatigue result from separate human needs. While burnout results from the drive to achieve a specific goal, compassion fatigue is the result of the human impulse to help others (Figley, 2002). This important distinction is beneficial in pursuing research on compassion fatigue in educators because it suggests that the experience of teachers cannot necessarily be explained using a single construct, and that research on human experience should be treated as complex and interrelated. This perspective can guide a discussion on the value of applying different constructs when attempting to understand the social-emotional experience of teachers. Although psychological distress in the form of burnout may reflect the experiences of many classroom teachers, teachers working with students with exceptionalities may also experience psychological distress in the form of compassion fatigue given these teachers' emotional investment in providing effective supports for their students. 


\section{Methodology}

To gain a thorough understanding of social-emotional experiences of teachers working with students with exceptionalities in general education classrooms, we sought to elicit their perspectives through a series of individual interviews. Compassion fatigue and burnout were both applied as analytical lenses when reviewing interview transcripts. Demographic information of participants (e.g., gender, education, years teaching, classroom size, resources available) was also gathered to inform our interpretation of the findings. Participant recruitment utilized purposeful sampling through direct connections to a series of schools in southeastern Ontario and snowball sampling through personal connections known to one of us (Ziaian-Ghafari, principal investigator). Criteria for involvement included teachers within the elementary level in Grades 4 to 8 who also had general education classroom experience teaching students with identified and unidentified exceptionalities.

\section{Participants}

Participants for this study included five educators, all between the ages of 25 and 40 years, each lived in Ontario, and each had taught students with exceptionalities in elementary school classrooms. Four participants had previous in-service experience and one participant was a current in-service teacher. Participants had a range of experience in the general education classroom and withdrawal or special education specialized settings. General education refers to contexts wherein students with exceptionalities are integrated into the classroom alongside the general student population. Withdrawal or specialized settings for support refer to services or programs that provide instruction and assessment separate from the general student population. All individuals in this study had experience with graduate studies related to the field of education. Pseudonyms are used instead of participant's real names.

Allison. Allison was an educator with less than one year of experience working in the general education classroom at an elementary public school. As a long-term occasional teacher (synonymous with substitute or supply teacher), Allison taught a class of approximately 25 students, with 6 students having identified or unidentified exceptionalities. Allison described herself as an adaptive teacher and viewed successful inclusion as being aware that a range of responses are necessary based upon contextual and situational aspects within the classroom. At the time of the interview, Allison was enrolled in a graduate studies program in education, pursuing research related to exceptionalities.

John. John was an educator with 9 years of teaching experience at the elementary school level. John's in-service teaching experience included the general education classroom as well as a specialized resource classroom for students with ASD. As a general classroom teacher, John taught a class of approximately 30 students, with 5-10 students each year with identified or unidentified exceptionalities. John described his professional identity as that of a teacher who protects his students from the educational and personal challenges they face. At the time of the interview, John was enrolled in a graduate studies program in education, pursuing research related to exceptionalities. 
Ethan. Ethan is an educator with 3 years of teaching experience at the elementary school level. Ethan's teaching experience included occasional teaching in the general classroom as well as a specialized education program for students with exceptionalities. As an occasional teacher, Ethan would typically teach classroom sizes of approximately 25 students, with approximately 5 students each year having identified or unidentified exceptionalities. Within the specialized educational program, Ethan gained experience working with approximately 12 students with exceptional educational needs. Ethan described himself as a teacher who is tactful, patient, and supportive. At the time of the interview, Ethan was enrolled in a graduate studies program in education, pursuing research related to exceptionalities.

David. David was a teacher with one year of teaching experience at the elementary school level. David's experience was at a high-needs school and included working with approximately 17 students with individualized education plans (IEPs) for both identified and unidentified exceptionalities. Class sizes ranged from 18 to 25 students. At the time of the interview, David had recently completed a graduate studies program in education.

Emily. Emily was a teacher with 10 years of experience at the elementary school level. Throughout her career, Emily gained experience as a general classroom teacher as well as a methods and resource teacher directly supporting students with exceptionalities within the larger school context. As a methods and resource teacher, Emily supported approximately 20 students with exceptionalities. Emily expressed her professional identity as one of an ongoing learner, working to provide the most effective support for students with exceptionalities. At the time of the interview, Emily was enrolled in a graduate studies program in education, pursuing research related to exceptionalities.

\section{Procedure}

A 90-minute semi-structured individual interview was conducted with each participant to gain a deeper understanding of the nature of their experiences working with students with exceptionalities. Prior to his interview, John requested a review of the questions and the other participants, with exception of David, were provided with that option. As the first participant, the interview with David had already been completed at the time of John's request and he could not be offered this same courtesy. Though questions were not altered based on the participant's review, this aspect of the procedure may have impacted the depth of reflection from David, since he did not have the time to consider his answers prior to the interview. All interviews were audio-recorded and transcribed verbatim. Participants were provided with an opportunity to read their transcript before it was analyzed and to remove any material they were uncomfortable disclosing. No participant requested that any material be excluded.

A series of questions was asked to access the nature of participants' experiences when working with students with exceptionalities. The interview questions were used to collect relevant demographic information, perceptions of inclusion of students with exceptionalities in general classroom settings, the challenging and rewarding aspects of teaching students with exceptionalities, the experience of autonomy in their professional

roles, feelings of success as an educator, relationships with other educational professionals, and the perceived impact of teaching on their physical and emotional health. 


\section{Analysis}

We managed the thematic coding manually. Each interview transcript was read individually by the first author. The analysis process began with deductive analysis directed at identifying codes that highlighted key features of burnout and compassion fatigue (Creswell, 2013). In the analysis of the transcripts, experiences related to burnout were defined as the psychological distress that resulted from the workload conditions of the participants. Experiences related to compassion fatigue were defined as psychological distress resulting from the social-emotional relationship between professionals and their clients. The key components of each of these constructs were used as interpretive lenses through which to understand teachers' experiences. All codes across participant transcripts were compared for duplications and overlapping descriptions. Similar codes were grouped and a description was written to encompass the code group. Inductive analysis was then conducted to identify the sub-themes that captured the nature of participants' experiences (Creswell, 2013).

\section{Results}

Compassion fatigue emerged across three themes: challenges with inclusion, personal investment in meeting students' needs, and limited resources to support success.

\section{Challenges with Inclusion}

The challenges that come with integrating students with exceptionalities into the general education classroom arose in each interview. Although John favours full inclusion of students with exceptionalities in classrooms, he questioned its practicality in whether classroom teachers have the necessary qualifications and preparedness for effectively supporting students with exceptionalities:

What we have are these kids with these profound challenges being sometimes dumped into a general education classroom. And, if that teacher doesn't happen to have his or her specialist in ASD or Spec-Ed [special education], that teacher is going to be overwhelmed.

John further discussed inclusion as a balance between being delicate and deliberate: "Sometimes academic success and emotional well-being are actually working in opposite directions, in that you can do a lot of good for a kid academically, and inadvertently do a lot of damage to their emotional well-being." For John, successful inclusion of exceptional students required the teacher to be cognizant of the students' socialemotional needs as well as their academic needs. This pursuit of balance ultimately added to his perceived responsibilities:

I had to build lessons for these small groups that were clearly set up, and all of this had to be done in a delicate way so that no one had the sense that they were being isolated or pulled out.

Emily discussed her experience as a resource teacher working with a specific student and their classroom teacher who was not inclusive in her practice:

She wasn't really good at accommodating, she wasn't flexible, and so she came into a lot of conflict with the child, and she thought that the child was being willful on purpose. She didn't understand the reasons behind his behaviour so it was very difficult trying to help her. 
Here, Emily's experience underscored the challenges of integrating exceptional students when teachers hold rigid perspectives and have limited understanding of exceptional students. For David, balancing the multiple needs of students with exceptionalities was challenging despite his best efforts, with certain activities inevitability limiting the participation of some students. Teaching in a high needs school, David expressed the often-occurring challenges for him to meet the needs of all students with exceptionalities integrated into his general education classroom:

I try to reach every student, and in some cases, it doesn't work because this activity really doesn't work for a certain student, or this student has a very intense writing disability, which means that he can't participate in this.

Allison questioned the benefits of inclusion for a particular student of hers:

I often wonder how beneficial it was for him to be integrated into the classroom because his exceptionalities were behavioural.... I do think that it's quite beneficial to integrate students in certain cases, I'm weary of blanket terms or blanket solutions.

Further, Allison appeared to experience remorse associated with not successfully integrating her student with an exceptionality fully into the classroom and the school's inability to support the success of that student,

I feel bad that ... we couldn't even offer the same kind of support that he got in that program in the school. He had to be pushed to suspension instead of [having] those kinds of supports within his daily school life.

These teachers often described instances in which integrating a student into the general classroom was not implemented effectively, leaving both the student and the teacher to face additional obstacles.

Reflecting this sentiment of a double-edged sword of full inclusion, John reflected on the balancing of the students' needs with those of the teacher. "They [students] require different strategies, and I framed that as a positive thing, but that actually can also be a negative thing as well." John continued, "I think the well-being and growth of teachers is maybe not as important as that of the students, but it's like one of those [situations], in an airplane you have to put your own oxygen mask on first, right?" For John, the well-being of the teachers working in inclusive classrooms is tied directly to supporting the needs of all students, with the pressures placed upon teachers surfacing as psychological distress that in turn can negatively impact the well-being of students.

Similar to John, David also discussed feelings of frustration that he experienced working with students with exceptionalities in the general education classroom:

It gets frustrating when I have one student who will not stop talking... I know it's because he has very intense ADHD [attention-deficit/hyperactivity disorder], and he's got a number of learning exceptionalities, but he has not come around like the other kids who have similar issues. I find [the behaviour piece] very challenging, and I find that's been a recurring issue for me when working with children with exceptionalities

The challenging behaviour and the difficulties he experienced trying to support students with exceptionalities appears to have had a negative impact on David's emotional well-being. 
As highlighted by Allison, another challenge of full inclusion of students with exceptionalities was emotionally negotiating differences in perspectives of challenging students between her and her fellow teachers:

I didn't want to go to colleagues who I knew would automatically turn to bashing the kids because that's not what I'm there for. I'm not there to listen to you bad mouth students, I'm here because I feel like I'm struggling with something.

John reflected on similar experiences:

I was really frustrated by other teachers, in fact for most of my career I just totally avoided the staff room ... I'm really embarrassed of the profession when I go into a staff room. There's just so much ugliness in those places.

While some teachers may use the staff room as an opportunity to express frustrations, the negative conversation about students with exceptionalities can further internalize other negative social-emotional experiences of teachers who attempted to maintain positive perspectives of the exceptional students with whom they worked.

Having experienced teaching in the general education classroom as well as a specialized classroom for students with ASD, John offered a unique insight into the differences between these contexts: "The relationship between kids with ASD and their teacher appears relative to the general education classroom to be absent of that emotional back and forth." John continued with an analogy describing the continuously satisfying nature of working with typically developing students in the general education classroom, "The general education classroom is like being in the hospital and having an adrenaline drip into your IV like 'bloop bloop'. It's constant, you're always feeling 'yeah this is wonderful."' In contrast, John emphasized that working in the specialized education classroom included satisfying experiences with students that were powerful but occurred much less frequently:

It happened rarely but it's like that scene in Pulp Fiction, to push the metaphor of the adrenaline. There's a scene where one character, his heart stopped, and so the other character takes a syringe and then plunges the adrenaline directly into his heart. And that's what it feels like being in a special education classroom. Nothing for days, and then something will happen ... that's amazing!

For John, the emotionally reciprocal nature of the environment in the general education classroom was distinct from that of the special education classroom, in that the former appeared to provide a consistent source of positive emotional support for him.

Ethan highlighted how the struggles experienced by an exceptional student can be internalized by a teacher. He described his difficulty watching an exceptional student who was unwilling to attempt to overcome any obstacles:

When I see a student demonstrating learned helplessness, or for whatever reason deciding that they can't do something, so they aren't even going to try, like, "I have ADHD so I'm not even going to try and focus, I can't," and that really frustrates me to see that, when they just give up.

Although Ethan did not express any blame toward the student, witnessing the negative impact that having an exceptionality can have on a student's motivation and confidence frustrated him. Conversely, Ethan emphasized the reciprocal nature of positive 
experiences between a teacher and an exceptional student, "One of the most satisfying things is seeing students say, 'I know I've got a learning disability but I can still read, I can overcome this." Despite the obstacles that come with inclusion of students with exceptionalities into the general education classroom, witnessing exceptional students overcome barriers to success was viewed as powerful and rewarding to teachers.

\section{Personal Investment in Meeting Students' Needs}

Aspects of psychological distress related to difficulties meeting the individual needs of students with exceptionalities were a prominent theme across all participants. John perceived his role not just as an educator but also as a support to protect his students from the various pressures they experienced inside and outside of the classroom. John reflected on the need to appreciate and understand the lived experiences of his students and how their experiences outside of the classroom can influence an exceptional student's life within the classroom. He described an experience with an exceptional student who had significantly disrupted his classroom. A follow-up meeting with the student indicated that he had experienced a traumatic incident the night before. John described the incident in the student's words:

It's like 3 o'clock in the morning and my dad drove me over to my mom's place and then he tied a chain around the cherry tree in the front yard and then he chain-sawed the tree down and he dragged the tree back to his house.

John later reflected on the story and the impact the incident might have had on his student: "That was what this kid was going through that night. So, I mean what an emotionally impactful experience that would have been, and had that happened to me I wouldn't care about mean median mode, either." For John this highlighted the position of the teacher in relation to his responsibilities as an educator and the holistic daily experiences of their students,

trying to understand the child not just as a passive recipient of knowledge and me as the prophet teacher ... understanding them as people and as humans, and you're offering them the dignity of being able to have a bad day, and that's actually okay.

Ethan also discussed the influential significance a student's life outside of the classroom can bring into the classroom, emphasizing his difficulty in protecting and supporting the student: "If I know a student is going through something tough, I think that really affects me, too, because I feel responsible, and I feel obligated to do something, and I can't always." Ethan, and other participants, often felt distress in the form of frustration when they became aware that a student was experiencing significant challenges outside the classroom but were unable to provide effective in-class or out-ofclass supports. A heightened sense of responsibility to ensure the needs of their students were being met irrespective of the school setting, coupled with limitations on responding to student's negative experiences, were notable sources of distress for these teachers.

For Allison, meeting the needs of all students and effectively supporting exceptional students was hindered by curricular expectations and time constraints:

I feel like when you're trying to accomplish five things in a 40-minute period and you don't feel like you're accomplishing any of them, that can take a real toll on the teacher as 
well... I'm not meeting the needs of this one student, I'm not meeting the needs of the classroom, and then I just feel exhausted.

Like Allison, John described feeling psychologically exhausted from continuous efforts, successful and unsuccessful, to meet the needs of exceptional students:

When you have a kid who is not integrating and not being successful, then you're either unable to do something to help them or you're trying and it's not having an effect, that's going to end up being really emotionally draining.

For John and Allison, an important aspect of feeling competent as a teacher was meeting the needs of all students and witnessing a student with an exceptionality struggle with integrating into the classroom was disheartening.

John drew attention to the necessary balance between emotional distress and emotional supports, and the pressure this can bring to a teacher,

The difficult thing is that these students need [an extra heaping of patience] more than everyone else, yet as a characteristic of how they interact in the classroom it's more effortful for us to even give them what everyone else needs.

In John's perspective, the challenges of helping students with exceptionalities in the general classroom can have a direct negative impact on the social-emotional experiences of teachers. Moreover, while it is common for teachers of exceptional students to experience psychological distress (e.g., frustration, emotional fatigue), the psychological needs that underlie successful outcomes of students with exceptionalities require teachers to maintain positive stances of patience and engagement while supporting these students. Importantly, John did not lack empathy toward difficult students; rather, he approached students' challenging behaviour as a function of their circumstances: "It's clear to see why it's happening, but that doesn't take away from the fact that it sucks everyday being that kid's teacher; there are some kids whose experience and life situations makes it hard to be their teacher." While John did not express blame toward students, he did acknowledge the demanding environment students with exceptionalities can potentially create for the teachers.

Allison's description of guilt and rumination around a salient experience in which she felt she was not meeting the needs of her students with exceptionalities is indicative of psychological distress. Allison described the aftermath of an incident between two students in which a confrontation in the hallway later erupted in a physical education class:

They got into this huge fist fight after they left my class. And as a result, one of the students, the student with the exceptionality, ended up getting suspended. And I keep going back to that being like, ah, I could have, I should have known, there should have been, like, some kind of intuition.

Her inability to support the student manifested as self-blame in her not seeing beyond the initial incident. The social-emotional relationship between the teacher and her student had implications for Allison's well-being. Following the suspension from school the student was temporarily placed in a specialized program. Allison discussed a conversation she had with the student upon his return to the general classroom: 
I think because we had that conversation, I didn't want him to think that he was a bad kid because he wasn't a bad kid. He's just a kid who maybe on one day wasn't set up to make the right decisions, and that was my job as a teacher.

Allison absorbed the responsibility for the student's actions during that particular event, displaying an urge to help and protect the well-being of the student with an exceptionality at the cost of her own well-being. Similar to John's perspective on the incongruity between a teacher's emotional experiences and the psychological needs of exceptional students, Allison's perspective highlights the need for teachers to be continuously aware and attentive to students' difficulties even in the presence of a teacher's own emotional challenges. The onus of continuous attention in supporting the success of exceptional students influenced teacher's emotional well-being beyond the classroom, Allison reflected:

I felt like it was my duty to do every single thing needed to meet their needs, and that ate into my personal life tremendously. To the point I, after that LTO [long-term occasional contract] I had to sit down with myself and say, "Never again, you can't ever put yourself in that situation again."

Feeling overwhelmed by the duty to meet the needs of her exceptional students pushed Allison to compromise the balance between her work and personal life, which ultimately contributed to experiences of psychological distress. Allison could identify the reduced well-being she experienced as a teacher, while also emphasizing that it limited the support she was able to provide her students. David expressed similar feelings of a reduced ability to meet specific needs of his students:

I just find that it's hard for me to care about the little things. I would say that if a kid has an actual problem, then I'm never too emotionally drained to help.... I'd like to think that I'm there for them when they need it the most.

David expressed a need to compromise between his empathy to meet the needs of his students that he judged as trivial in order to better support his students experiencing more significant difficulties.

Emily held a similar perspective to that of other participants with respect to the need to balance through compromise when attending to students' individual needs and her own psychological well-being: "The whole day was kind of a bizarre day, and you had to deal with a lot of student issues ... and still maintain your own sense of calm and well-being." When asked if she ever considered the need to take time off, Emily responded, "Not that I never wanted to, but teaching is a job where you're required to be there. That is the main part, you've got to be there, and you do feel extremely responsible for your students." For Emily, taking time away from the classroom to support her own well-being meant compromising the needs of her students.

\section{Limited Resources to Support Success}

A discussion of the resources - in terms of professional and collegial support as well as tangible curricular and instructional supports that were available to teachers to support students with exceptionalities - emerged across all participant interviews. The absence of these forms of support appeared to create feelings of isolation in participants. John suggested that when he taught within an ASD classroom, he often felt alone because 
pedagogical experiences and discussions tended to focus on a teacher's own classroom context, with sharp distinctions drawn between general educational settings and settings for specialized programming. In essence, commonalities among experiences and suggestions for alternative approaches for adaptations were not readily transferable across settings: "I think working with students with exceptionalities can be really isolating because the further you move from the default normative expectations for teaching the less you have in common with people around you." In contrast, David, who worked primarily with exceptional students in a general education classroom, found that many resources were available at his school and proved to be important components in his success and in mitigating the emergence of psychological distress:

There's a lot of support at this school, and there was some support at my last school as well from the admin and from the other teachers - getting those resources and, especially as a new teacher, learning how to curb those ... frustrations.

Allison appeared to have a different experience to that of David:

Whether it was a time issue or whether it was a resource issue or me feeling overwhelmed by all the things I needed to accomplish ... well, is this just the system, then? Are these just the resources we have available to them, or is this just the way it is for students with exceptionalities?

Allison also discussed the limitations of relying on her schools' resource teacher: "He has the training to handle behavioural exceptionalities. He's supposed to be the goto, but he can't even make face time in the classroom because he has other things going on in the school." Although the school offered the knowledge and experience of a resource teacher to help support student success, that support was difficult to access due to the overwhelming demand, ultimately leaving general classroom teachers like Allison to cope alone. Emily articulated a different perspective on resource supports as she discussed her role as the special education resource teacher at her school: "Because my job allowed me to go into different classrooms, I was able to try to bring that different perspective to other teachers, and it was difficult when they didn't see that as positive or as helpful for them." While Allison was unable to access the resource teacher at her school, as a resource teacher Emily found herself encountering resistance from general classroom teachers when providing support for students with exceptionalities in the general classroom. John also discussed stigma associated with teachers disclosing to colleagues the frustrations they experience working with students with exceptionalities:

You don't want to admit to colleagues that you're having a difficult time.... There's some stigma around even asking "how do you help this kid out because you have a monster, what did you do with it?" so the bulk of the responsibility for helping these kids out ended up being on me, the individual teacher.

Throughout his interview John expressed that as a teacher he often felt like a "lone wolf" in managing the obstacles of working with students with exceptionalities and felt unable to ask for support from his colleagues.

Teachers' knowledge and training. While more typically associated with burnout in human-service professionals, a lack of training and knowledge emerged as a sub-theme related to resources and student supports with our educational professionals. Our participants, however, associated these challenges with negative emotions reflective of 
compassion fatigue, which resulted from inabilities to fully and successfully support their students with exceptionalities. Discussing the integration of students with physical exceptionalities in physical education classes, Ethan expressed the challenge of supporting student success with a limited understanding of how best to design the lesson for a specific exceptionality, particularly as classrooms are expected to be openly accessible to a wide range of exceptionalities: "Another would be a lack of educationsome exceptionalities I just don't know a lot about." He continued, "It can be frustrating when you, as a teacher, don't have the appropriate resources. I'm thinking of an IEP in this case, that says these are the exact [challenges] that we have identified with this student." While seeking support from colleagues was not always a viable option for some teachers, as noted by John and Allison, others looked to their administration for guidance when struggling with fully including exceptional students in their classroom. David described the importance of the administrative team at his school:

Our vice principal is part student support, so I find myself going to [this person] as well as the principal. She's an amazing resource, especially since I'm new, I'm getting to know the school and the kids, so going to those [two] people has been a huge help. My principal has been amazing, just learning from her and talking to her about stuff like pedagogy.

David concluded his reflection upon these supports stating, "That's definitely helped keep me here in the profession." In the face of significant struggles supporting his exceptional students, administrative support appeared to minimize the psychological distress David experienced and likely contributed to his remaining a teacher.

\section{Discussion}

Psychological distress (e.g., burnout and compassion fatigue) is an important deciding factor in teachers leaving their profession of choice. Although participants in the present study did not experience compassion fatigue at levels that would have necessitated their completely exiting the profession, elements of compassion fatigue were evident throughout their dialogue. This suggested that compassion fatigue may be a relevant lens through which to understand experiences of psychological distress in teachers working with exceptional students. Notable elements of compassion fatigue emerged in participants' discussions regarding the challenges with inclusion, personal investment in meeting students' needs, and limited resources to support success.

Teachers witnessing a student who has not been successfully integrated into the general education classroom may be susceptible to compassion fatigue. Inclusion of exceptional students into their classroom can pose challenges beyond those experienced by teachers who work diligently to support the individual needs of students not identified as students with exceptionalities (Brackenreed \& Barnett, 2006; Hillel Lavian, 2015). These responsibilities encapsulate attending to all students' social, emotional, behavioural, and academic needs. Teachers who are able to feel effective in balancing the needs of all students, in particular the students with exceptionalities who require additional support in their classroom, limit their risk of experiencing psychological distress reflective of compassion fatigue. In the absence of finding an effective balance, general education classroom teachers are susceptible to experiences indicative of compassion fatigue (Hoffman et al., 2007; Tepper, 2007). Allison experienced guilt 
associated with the unsuccessful integration of her students with an exceptionality into her classroom and the schools' inability to support exceptional students' success because of insufficient resources. Teachers, particularly those invested in the success of exceptional students, may experience psychological distress when exposed to the distress of these vulnerable students in a manner similar to that of other human-service professionals, such as nurses, who maintain a similar social-emotional investment in their clients (Bride et al., 2007).

As highlighted in our participants' interviews, the psychological well-being of teachers and students is reciprocal in nature: Clearly the well-being of teachers supported the well-being of students, and students' well-being supported teachers' well-being. The bi-directional social-emotional relationship between students and teachers extends beyond general well-being and also has an influence upon professional efficacy and fulfillment. Consistent with the research by Skaalvik and Skaalvik (2010) teachers' selfefficacy and job satisfaction are related to their emotional experiences in working with students. While our participants' experiences are in accord with these findings, we also found a disruption in this process, whereby teachers experiencing psychological distress reflective of compassion fatigue felt a lack of efficacy in successfully supporting the academic and social-emotional needs of their students with exceptionalities.

A notable source of disruption of the reciprocal nature of shared positive socialemotional experiences for some teachers was found when seeking support from colleagues. While many teachers use the staff room as an informal setting to discuss daily experiences within the profession and to seek support from more experienced teachers (Schlichte et al., 2005), some may use the staff room as an opportunity to express frustrations with students. When conversations about students with exceptionalities took a negative tone, our participants tended not to internalize other's negative perceptions; rather, they felt a loss of social-emotional support in that they did not feel comfortable seeking support from colleagues who appeared at times to hold disparaging views of students. In essence, teachers' vicarious experiences of the stigma and challenges encountered by students with exceptionalities and the negative expectations of their success appeared to contribute to feelings reflective of compassion fatigue in our teachers. Although participants also experienced frustration at times working with their exceptional students, they did not express any blame toward these students. Instead, much of the emotional distress related to frustration emerged in response to repeated exposure of the negative impact that having an exceptionality can have on a student's motivation and self-confidence.

John, as did the other participants, acknowledged the demanding environment exceptional students can potentially create for teachers. Exceptional students, by definition, have additional educational needs compared to typically developing children. Thus, integrating exceptional students into general education classrooms can potentially increase the pedagogical demands on teachers and influence their psychological wellbeing (Hillel Lavian, 2015). With respect to the latter, our participants often spoke directly to feelings of emotional exhaustion, depersonalization, and reduced feelings of personal accomplishment reflective of burnout-perceptions that are characteristic of stressors experienced by many teachers (e.g., Maslach, 2003). However, in contrast to burnout, in which these feelings are related to workload conditions, when our participants 
articulated experiencing these emotions, they did so within the context of feeling unable to effectively support their students with exceptionalities. This dynamic appeared to be a double-edged sword for our participants. The psychological distress experienced by participants was rooted in their difficulties to successfully support their exceptional students. Their enduring passion for being an effective advocate and educator for their exceptional students is also what kept them focussed in the classroom.

A long-term potential consequence of burnout and compassion fatigue experienced by teachers of exceptional students is leaving the profession or moving to a different setting within the profession that is not focussed on exceptional students (e.g., Connelly \& Graham, 2009). It is noteworthy that while each of our teacher participants experienced psychological distress related to compassion fatigue, they remained within the field of education, with each pursuing graduate studies in the area of special education. With the underlying impetus to effectively support their students, akin to the motivations of other human-service professionals such as nurses and social workers (Najjar et al., 2009), it is not surprising that teachers of exceptional students are at risk for leaving the profession if they feel unable facilitate positive outcomes for their students. Participants not only sought higher education that was related to self-improvement and growth; it also appeared to be a consequence of their work with students with exceptionalities. These teachers wanted to increase their knowledge, understanding, and ability to provide support for their students, whom they often witnessed as struggling in the general education classroom. This suggested that working with exceptional students challenged these educators to be better teachers for their students. Their work with students with exceptionalities did not push them out of the field of education; rather it appeared to encourage participants to seek learning and experience related to better teaching for students with exceptionalities in a graduate school setting. In the face of compassion fatigue our participants were able to maintain their passion for supporting exceptional students and to mitigate significant psychological distress they might have experienced by redirecting their focus away from classroom practice; they were able to follow a continuing education path where they could develop a better understanding of the experiences of students with exceptionalities and perhaps develop more effective strategies for supporting them and meeting their needs.

\section{Limitations}

In addition to the small sample size of the present study, an important limitation is the demographic characteristics of the participants. Three of the teachers in this study were in the early years of their career and two (Emily and John) as experienced educators spent a significant amount of time in specialized classrooms. Thus, their perspectives are not necessarily representative of the typical experiences of teachers working with exceptional students in general education classrooms. An important direction for future research would be to examine psychological distress in relation to burnout and compassion fatigue by comparing the experiences of teachers assigned to specialized classrooms for exceptional students to those of teachers working within full-inclusion classrooms. Further, studies are needed that explore those factors that allow teachers to thrive when experiencing obstacles within inclusive settings. 


\section{Conclusions}

Although the data from this study did not suggest that participants experienced compassion fatigue at a level that initiated their leaving the profession, elements of this construct did emerge as relevant to the social-emotional experiences of the teachers. Interviews with educators in the present study suggested that the trajectories toward burnout and compassion fatigue for teachers of exceptional students were circumvented by their concerted and consistent focus upon supporting positive social-emotional experiences of their students.

A possible explanation for the limited psychological distress is that four of the five participants were not current in-service teachers and had left the profession to pursue graduate studies. In the context of teachers working with students with exceptionalities, burnout did not emerge as essential to the experiences of the participants. When elements of burnout did surface, these experiences were not related to dissatisfaction with their job; rather, participants related these experiences directly to an inability to support their students with exceptionalities, which is more representative of compassion fatigue. Positioning the root of burnout as being related to workload conditions and that of compassion fatigue as resulting from the social-emotional relationships with students, it is possible that compassion fatigue and burnout surface along parallel trajectories of psychological distress in teachers. In light of concerns over teacher attrition during the early stages of their careers (e.g., Karsenti \& Collin, 2013), understanding the possible parallel paths that cause psychological distress in teachers will help administrators and school systems to target interventions that address the specific sources of distress. Although working with students with exceptionalities in the general classroom might add to the volume of work for a teacher, it is the relationship with students with exceptionalities and the impulse of the teacher to help them that contributed to experiences of psychological distress for participants. Considering the significance of teachers' relationships with students, teachers struggling with psychological distress may benefit from reflecting on the nature of their social-emotional interactions with students. Recognizing their limitations as a teacher in meeting the needs of every student can help protect teachers from the elements of psychological distress reflective of compassion fatigue. Future research on the social-emotional experience of teachers working with exceptionalities may be better situated using the construct of compassion fatigue.

\section{References}

Brackenreed, D., \& Barnett, J. (2006). Teacher stress and inclusion: Perceptions of pre-service teachers. Developmental Disabilities Bulletin, 34, 156-176.

Bride, B. E., Radey, M., \& Figley, C. R. (2007). Measuring compassion fatigue. Clinical Social Work Journal, 35(3), 155-163.

Brouwers, A., \& Tomic, W. (2000). A longitudinal study of teacher burnout and perceived selfefficacy in classroom management. Teaching and Teacher Education, 16(2), 239-253.

Conderman, G., Johnston-Rodriguez, S., Hartman, P., \& Walker, D. (2012). Honoring voices from beginning special educators for making changes in teacher preparation. Teacher Education and Special Education, 36(1), 65-76. 
Connelly, V., \& Graham, S. (2009). Student teaching and teacher attrition in special education. Teacher Education and Special Education, 32(3), 257-269.

Creswell, J. W. (2013). Qualitative inquiry and research design: Choosing among five approaches (3rd ed.). Thousand Oaks, CA: Sage Publications.

Desrumaux, P., Lapointe, D., Sima, M.N., Boudrias, J.S., Savoie, A., \& Brunet, L. (2015). The impact of job demands, climate, and optimism on wellbeing and distress at work: What are the mediating effects of basic psychological need satisfaction? Revue Européenne de Psycholgie Appliquée/European Review of Applied Psychology, 65(4), 179-188.

Emery, D. W., \& Vandenberg, B. (2010). Special education teacher burnout and ACT. International Journal of Special Education, 25(3), 119-131.

Everhart, B. (2009). Anxiety of preservice teachers teaching students with disabilities: A preliminary investigation. Education, 129(4), 704-713.

Figley, C. R. (2002). Treating compassion fatigue. New York, NY: Brunner-Routledge.

Graf, C. M., Millar, S., Feilteau, C., Coakley, P. J., \& Erickson, J. I. (2003). Patients' needs for nursing care: Beyond staffing ratios. Journal of Nursing Administration, 33(2), 76-81.

Hillel Lavian, R. (2015). Masters of weaving: The complex role of special education teachers. Teachers and Teaching, 21(1), 103-126.

Hoffman, S., Palladino, J. M., \& Barnett, J. (2007). Compassion fatigue as a theoretical framework to help understand burnout among special education teachers. Journal of Ethnographic \& Qualitative Research, 2(1), 15-22.

Hultell, D., Melin, B., \& Gustavsson, J. P. (2013). Getting personal with teacher burnout: A longitudinal study on the development of burnout using a person-based approach. Teaching and Teacher Education, 32, 75-86.

Karsenti, T., \& Collin, S. (2013). Why are new teachers leaving the profession? Results of a Canadawide survey. Education, 3(3), 141-149.

Learning Disabilities Association of Ontario. (2018). Learning disabilities statistics [Web page]. Retrieved June 8 from the Learning Disabilities Association of Ontario website, http://www.ldao.ca/introduction-to-ldsadhd/articles/about-lds/learning disabilities-statistics/

Maslach, C. (2003). Job burnout new directions in research and intervention. Current Directions in Psychological Science, 12(5), 189-192.

Maslach, C., \& Jackson, S. E. (1981). The measurement of experienced burnout. Journal of Occuptional Behavior, 2(2), 99-113.

Ontario Ministry of Education. (2017). Special education in Ontario: Kindergarten to Grade 12: Policy and resource guide (Draft report). Toronto, ON: Author. Retrieved from http://www.edu.gov.on.ca/eng/document/policy/os/onschools_2017e.pdf

Najjar, N., Davis, L. W., Beck-Coon, K., \& Carney Doebbeling, C. (2009). Compassion fatigue: A review of the research to date and relevance to cancer-care providers. Journal of Health Psychology, 14(2), 267-277.

People for Education. (2015). Ontario's schools: The gap between policy and reality (Annual report on Ontario's publicly funded schools, 2015). Toronto, ON: People for Education.

Perry, N. E., Brenner, C., Collie, R. J., \& Hofer, G. (2015) Thriving on challenge: Examining one teacher's view on sources of support for motivation and wellbeing. Exceptionality Education International, 25, 6-34.

Putnik, K., de Jong, A., \& Verdonk, P. (2011). Road to help-seeking among (dedicated) human service professionals with burnout. Patient Education and Counseling, 83(1), 49-54 
Radey, M., \& Figley, C. R. (2007). The social psychology of compassion. Clinical Social Work Journal, 35(3), 207-214.

Schlichte, J., Yssel, N., \& Merbler, J. (2005). Pathways to burnout: Case studies in teacher isolation and alienation. Preventing School Failure: Alternative Education for Children and Youth, $50(1), 35-40$.

Shippen, M. E., Crites, S. A., Houchins, D. E., Ramsey, M. L., \& Simon, M. (2005). Preservice teachers' perceptions of including students with disabilities. Teacher Education and Special Education, 28(2), 92-99.

Skaalvik, E. M., \& Skaalvik, S. (2010). Teacher self-efficacy and teacher burnout: A study of relations. Teaching and Teacher Education, 26(4), 1059-1069.

Statistics Canada. (2008). Educational services and the disabled child [Web page]. Retrieved June 8, 2018, from the Statistics Canada website, http://www.statcan.gc.ca/pub/81-004x/2006005/9588-eng.htm

Tepper, E. L., \& Palladino, J. M. (2007). Compassion fatigue and burnout: Precursors to elementary special educators' exodus from teaching (Online submission). Retrieved from ERIC database (Doc. ED522930), http://www.eric.gov

Van den Berghe, L., Soenens, B., Aelterman, N., Cardon, G., Tallir, I. B., \& Haerens, L. (2014). Withinperson profiles of teachers' motivation to teach: Associations with need satisfaction at work, need-supportive teaching, and burnout. Psychology of Sport and Exercise, 15(4), 407-417.

Van Droogenbroeck, F., \& Spruyt, B. (2015). Do teachers have worse mental health? Review of the existing comparative research and results from the Belgian Health Interview survey. Teaching and Teacher Education, 52, 88-100.

Wang, H., Hall, N. C., \& Rahimi, S. (2015). Self-efficacy and causal attributions in teachers: Effects on burnout, job satisfaction, illness, and quitting intentions. Teaching and Teacher Education, $47,120-130$.

Wash, P. D., \& Freeman, G. G. (2014). Teacher candidate insights into the fears and anxieties of the education profession. National Teacher Education Journal, 7(2).

\section{Authors' Note}

Correspondence concerning this article should be addressed to Dr. Derek H. Berg, Duncan McArthur Hall, Room A316, 511 Union Street, Queen's University, Kingston ON, K7M 5R7, Canada. Email: derek.berg@queensu.ca 